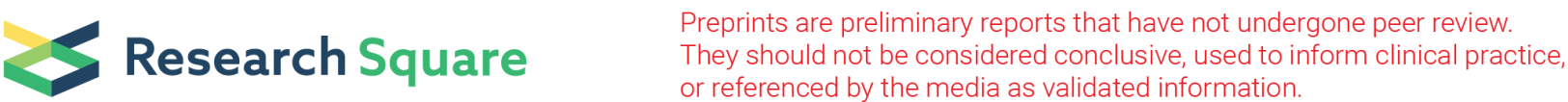

\section{Expression of Mitochondrial Progesterone Receptor (PR-M) in Ovarian Cancer and Its Effect on Cell Metastasis Induced by Progesterone}

\section{Qingqing Yang}

Zhengzhou University Third Hospital and Henan Province Women and Children's Hospital

\section{Chang Duan}

Zhengzhou University Third Hospital and Henan Province Women and Children's Hospital

\section{Haofan Wang}

Zhengzhou University Third Hospital and Henan Province Women and Children's Hospital

\section{Dongyuan Jiang}

Zhengzhou University Third Hospital and Henan Province Women and Children's Hospital

\section{Yaping Wang}

Zhengzhou University Third Hospital and Henan Province Women and Children's Hospital

\section{Qingfeng Tian}

Zhengzhou University

\section{Quanling Feng ( $\nabla$ zzufql@126.com )}

Third Affiliated Hospital of Zhengzhou University https://orcid.org/0000-0001-7333-8094

\section{Research article}

Keywords: PR-M, Ovarian cancer, Progesterone, Proliferation, The migration

Posted Date: March 3rd, 2021

DOl: https://doi.org/10.21203/rs.3.rs-285751/v1

License: (c) (1) This work is licensed under a Creative Commons Attribution 4.0 International License. Read Full License 


\section{Abstract}

Background: PR-M refers to a novel truncated progesterone receptor located on the outer membrane of mitochondria, capable of facilitating the proliferation of leiomyoma cells and breast cancer cells, as well as inhibiting apoptosis as impacted by progesterone or progesterone agonists. However, its role in ovarian tumors has not yet been elucidated.

Objective: To study the expression of PR-M in different ovarian tumor tissues and normal tissues, and the effect exerted by progesterone on the proliferation and migration of SKOV-3 cells that achieve high PR-M expression.

Methods: Real- time PCR and Western blot were employed for determining PR-M levels in cell lines, noncancer tissues and ovarian cancer tissues. By immunohistochemistry, PR-M protein expression in benign tumor, borderline tumor and epithelial carcinoma was detected, and the clinicopathological characteristics between PR-M and cancer were analyzed. Furthermore, CCK-8 and scratch test were performed to explore the proliferation and migration of SKOV-3 cells exhibiting high PR-M expression.

Results: PR-M increased significantly in cancer tissues and ovarian cancer cell lines, in comparison to normal cells and non-cancer tissues. The abnormal expression showed a significant correlation with intraperitoneal metastasis, lymph node metastasis, clinically related stage and CA125 level, suggesting that high PR-M expression may affect the progression of ovarian tumors. During the cell experiment, PR$M$ achieved the maximum expression in SKOV-3 cells (PR-A / B(-)). As impacted by progesterone, SKOV-3 cells (PR-A / B(-)) achieved the enhanced proliferation and migration. Besides, the enhancing effect was dose and time-dependent.

Conclusion: PR-M is critical to develop ovarian cancer. Progesterone may facilitate the proliferation and migration of ovarian cancer cells exhibiting high PR-M expression.

\section{Introduction}

Ovarian cancer refers to the most lethal gynecological malignant state. In addition, a high metastatic rate of ovarian cancer cells causes high mortality rates $(1,2)$. As impacted by the deep anatomical location of the ovary, early ovarian cancer exhibits few obvious abnormal signs, and it has rarely received accurate clinical experimental diagnosis. Nearly $70 \%$ of ovarian cancer patients are diagnosed as middle and late stages, and the mentioned patients achieved the 5 years surviving ratio of $20 \sim 30 \%(3-5)$. In nature, $90 \%$ of ovarian cancers are epithelial, and the major histological types consist of serous, endometrioid, mucinous and clear cells. High-grade serous carcinoma (HGSC) is considered to be the most frequently appearing histology-related subdivided type, which is followed by clear, low-grade serous cancer (LGSC), mucinous and endometrioid cells(6). Besides, chemotherapy after operative is recognized as the standard ovarian cancer treating process. Though progress is being made, this population has high recurrence and metastasis rates(7). 
Progesterone refers to a steroid hormone synthesized primarily by the corpus luteum in the ovaries. Moreover, small amounts of progesterone are generated in the adrenal glands and placental tissues in the course of pregnancy $(8,9)$. Progesterone acts as a vital factor regulating reproductive function, which is capable of affecting considerable tissues and organs (e.g., breast, uterus and ovary)(10). As considered by most studies, progesterone is capable of preventing ovarian cancer, inhibiting ovarian cancer cell proliferation, as well as inducing OSE cell and tumor cell apoptosis(11).

The effect of progesterone on female reproductive system is largely mediated by progesterone receptor (PRS) that is synthesized by single gene (PR) and expressed in two major protein subtypes (PR-A and PRB)(12). They act as ligand activated transcription factors and have the ability to mediate genomic effects (i.e., affecting gene expression). Overall, the response to progesterone is considered to be dependent of the combined action of PR-A and PR-B, which lead to the formation of homodimers or heterodimers after ligand binding and exhibit a unique transcriptional activity in specific gene promoter subsets $(13,14)$. However, besides the conventional nuclear hormone receptor PR-A and PR-B, some novel types of PR receptors were reported over the past few years (e.g., PR-C, PR-M, membrane PR (membrane progesterone receptor) and progesterone receptor membrane component 1 (PGRMC1)). There are two other transcripts, i.e., PR-S and PR-T(15-19). PR-M refers to a novel truncated progesterone receptor, cloned from human aorta and adipose tissue cDNA library by ThomasM.Price experimental team in 2002 (GenBank: AY212933.1)(16). PR-M was suggested to have the location on the outer membrane of mitochondria and the involvement in the regulation of cell respiration(20). As revealed from the results of Western blotting assay, PR-M was expressed as a $38 \mathrm{kDa}$ protein in Sf9 insect cells, aortic epithelial cells and T47D breast cancer cells $(21,22)$. PR-M was reported to increase mitochondrial membrane potential, facilitate the proliferation of cancer cells and suppress their apoptosis as impacted by progesterone agonists $(16,20)$. According to the latest research findings, PR-M expressing state in rat $\mathrm{H} 9 \mathrm{c} 2$ cardiomyocytes led to an elevation of oxidative cellular respiration and beta-oxidation that is determined by ligand(23). Given the mentioned analysis, PR-M expressing state in ovarian cancer tissues and non-cancer tissues was further explored, the proliferation and migration of ovarian cancer cells exhibiting high PR-M expression were observed by different concentrations of progesterone, and then the effect of progesterone on ovarian cancer from the non-genomic effect was determined.

\section{Materials And Methods}

\section{Study subjects}

Normal ovarian surface epithelial (OSE) tissue samples $(n=5)$ and serous ovarian cancer (SOC) tissue samples $(n=5)$ involved to conduct the paired study (Primary ovarian tumor tissues and matched adjacent normal samples) originated from the Third Affiliated Hospital of Zhengzhou University (Zhengzhou, China) between January and December, 2018, following ovarian cancer surgeries (patients aged from 30 to 65 ). Moreover, this study investigated SOC tissue samples of 80 patients having undergone surgeries for EOC at the Pathology Center of the Third Affiliated Hospital of Zhengzhou 
University (Zhengzhou, China) from 2014 to 2019. (patients aged from 20 to 65). The deadline for the follow-up was July 30, 2020.

\section{Ethical approval}

The present study received the approval from the ethics committee of the Third Affiliated Hospital of Zhengzhou University by complying with the standards specified in the declaration of Helsinki. The written informed consent of patients was obtained before they were enrolled, and the tissue samples were acquired.

\section{Western blot analysis}

Five pairs of paired ovarian cancer and non-cancer ovarian epithelial tissues (RIPA Buffer Solaibao Institute of Biotechnology) were cleaved by the Western blotting assay, The lysate was produced by the centrifugation at $4^{\circ} \mathrm{C}(12000 \times \mathrm{g}, 30 \mathrm{~min})$. The supernatant was cytoplasmic protein, which was then deposited into nucleoprotein. The cytoplasmic protein of the supernatant was introduced into the EP tube, and the protein concentration was measured with BCA protein determination kit. After $30 \mu \mathrm{g}$ cytoplasmic protein was applied onto $10 \%$ SDS-PAGE, the protein underwent the transfer to polyvinylidene fluoride membrane. After blocking ( $5 \%$ skimmed milk, $37^{\circ} \mathrm{C} 2 \mathrm{~h}$ ), the membrane underwent the incubation with PR antibody at $4{ }^{\circ} \mathrm{C}$ for $12 \mathrm{~h}$ (1:800 dilution; sc-166169; Santa Cruz Biotechnology), and then it was treated with horseradish peroxidase coupled secondary antibody (Goat anti-rabbit iggab6721, 1:5000, Abcam, UK) at $37^{\circ} \mathrm{C}$ for $2 \mathrm{~h}$. TBST solution was adopted to clean the film, 6 times, $5 \mathrm{~min} /$ time. Next, the gray value analysis of the obtained strips was conducted using gel image analysis software.

\section{Cell culture}

Five ovarian cancer cell lines (i.e., SKOV-3, H08910, 3AO, IOSE-80 and ES-2) and T47D breast cancer cells were offered by the Chinese Academy of Sciences (Shanghai, China). The cells underwent the culture in RPMI-1640 medium supported by fetal bovine serum (FBS). Moreover, T47D cells and SKOV3 cells underwent the culture in RPMI-1640 medium (Gibco; Thermo Fisher Scientific, Inc., Waltham, MA, USA) supplemented by $10 \%$ fetal bovine serum (FBS; Hyclone; GE Healthcare Life Sciences, Logan, UT, USA) at $37^{\circ} \mathrm{C}$ in $\mathrm{CO} 2$ incubating element under $5 \%$ humidity.

\section{Real-Time PCR}

Overall RNA was extracted from cells and clinical tissues with the use of Trizol reagent (Invitrogen, USA). Following the instructions of the producer, $1 \mu \mathrm{g}$ RNA underwent the transformation into cDNA (reaction system $10 \mu \mathrm{L}$ ) by employing RT for PCR kit (Takara, JPN). When $2 \mu \mathrm{L} c D N A$ received the mixing with SYBR green, $C F X 96^{\text {TM }}$ Real-Time system (bio RAD) was employed for quantitative real-time qPCR (RT 
qPCR) (reaction system $20 \mu \mathrm{L}$ ), including $95^{\circ} \mathrm{C} 5 \mathrm{~min}, 95^{\circ} \mathrm{C} 30 \mathrm{~s}, 56^{\circ} \mathrm{C} 30 \mathrm{~s}, 72{ }^{\circ} \mathrm{C} 30 \mathrm{~s}$, as well as 40 cycles. The primers for GAPDH consisted of: 5'-TTGGTATCGTGGAAGGACTCA-3', 5'-

TGTCATCATATTTGGCAGGTT-3'; the primers for PR-M included 5'-CAGATGTGATCTATGCAGGACATGA3',5'-TCATCCGCTGTTCATTTAGT-3'; GAPDH was classified as the internal control.

\section{Cell counting kit-8 assay}

PR-M mRNA achieved the maximum expression in SKOV3 cells. SKOV-3 cells had no expression of nuclear progesterone receptor (n-PR-A or -B) protein(24). 200 UL / well PBS was introduced around the 96 well plate. Subsequently, the cells underwent the process of digestion, centrifugation and resuspension. Moreover, the cell concentration was altered to $5 \times 10^{4}$ cells / $\mathrm{ml}$. The $100 \mathrm{UL}$ cell culture medium was introduced to the respective well. Five multiple wells were generated in the respective group. Under the cell growth fusion degree of $60 \%-70 \%$, medroxyprogesterone acetate (Progesterone) (Sigma, USA) was introduced. The concentration of P was 0 umol / L, 10 $0^{-7}$ umol / L (low P, L-P), 10-6 umol / L (moderate $\mathrm{P}, \mathrm{M}-\mathrm{P}$ ) and $10^{-5} \mathrm{umol} / \mathrm{L}$ (high P, H-P) for 24-48 h, and then 10UL CCK-8 solution was introduced to the respective well for 2-3 h. By enzyme-linked immunosorbent assay, the optical density of each well was determined at $450 \mathrm{~nm}$ wavelength.

\section{Scratch test}

SKOV-3 cells (PR-A/B (-)) were inoculated into the cell culture plate. Under the cell density of $80 \%$, a sterile 10ul gun was adopted to scratch the plate center, while the scratch distance was recorded. Subsequently, $10^{-5} \mathrm{umol} / \mathrm{L}$ progesterone was introduced to culture. Under an inverted microscope, the migration of SKOV-3 cells was detected at $24 \mathrm{~h}$ and $48 \mathrm{~h}$.

\section{Immunohistochemistry}

By immunohistochemistry, the expression of PR-M protein in 12 benign ovarian tissues, 8 borderline ovarian tissues and 32 ovarian cancer tissues was detected. In brief, $5 \mu \mathrm{m}$ thick paraffin embedded sections were baked at $60^{\circ} \mathrm{C}$ for $1 \mathrm{~h}$ and then dewaxed with xylene. Subsequently, the hydration and antigen repair were performed on the sections by the high-pressure treatment with EDTA buffer then cleaned with PBS 3 times. Next, the non-specific antibody was sealed with $50 \mu \mathrm{L}$ of $0.5 \%$ calf serum albumin for 15 min (1:500 dilution; sc-166169; Santa Cruz Biotechnology). PBS was classified as the negative control, and the positive control acted as the positive control. The positive control underwent the incubation in $4{ }^{\circ} \mathrm{C}$ refrigerator overnight. $50 \mu \mathrm{L}$ of biotin labeled Sheep anti-rabbit IgG (sigma) was added to the respective slice, and $50 \mu \mathrm{l}$ of streptavidin peroxidase solution (sigma) was added to each slice. Moreover, Tris buffer solution was adopted for 3-time shock washing, with 5 min each time. Under the microscope, $0.04 \%$ DAB-H2O2 was employed for coloring for 5-20 min. The nuclei were stained with hematoxylin, differentiated with alcohol, dehydrated with gradient ethanol, then transparent with xylene 
and subsequently sealed with neutral gum. Two pathologists, with no previous knowledge of the patient's clinical condition, were asked to observe the tissue after immunohistochemical staining and score by employing the double-blind method. Positive cell judgment criteria were elucidated: determining the protein expression level according to the cytoplasmic staining and the number of positive cells. Based on the staining intensity (i.e., colorless - 0 , light yellow - 1, Brown - 2 and Brown - 3), and then given the percentage of positive cells (i.e., the number of positive cells $\leq 10 \%$ was $0,10 \%-25 \%$ was $1,>25 \%-50 \%$ was $2,>50 \%-75 \%$ was 3 , and $>75 \%$ was 4 ), the staining intensity $\times$ percentage of positive cells $\geq 2$ was positive, and the staining intensity fraction $\times$ percentage of positive cells $<2$ was negative.

\section{Statistical Analyses}

Statistical analyses overall began by employing the statistical software package SPSS 25.0, and the measured data were expressed as mean \pm SD. The comparison between groups was drawn by one-way ANOVA or repeated-measures ANOVA. Tukey's post-hoc analysis was employed for pairwise comparison in groups. To determine the relationship between the expression level of PR-M protein and clinicopathological features, Fisher's exact test was performed. Furthermore, based on Spearman's rank correlation coefficient, the bivariate correlation was calculated. A P-value $<0.05$ was considered to show significant difference.

\section{Results}

\section{PR-M Expression Significantly Increased in Ovarian Cancer Tissues Compared with Normal Control Tissues}

By performing Western blotting assay and immunohistochemistry, this study assessed the expression of PR-M in ovarian cancer and normal control tissues. T47D breast cancer cells were classified as the positive control. If the IDV value of PR-M is compared with that of GAPDH, and the ratio of IDV in normal group is set to 1, the ratio of IDV in tumor group will exceed 1, demonstrating that the expression of protein in cancer tissue is more robust than that in no-tumor tissues. As revealed from the results, PR-M in most ovarian cancer tissues was significantly higher than that in adjacent no-tumor tissues (Fig. 1A, B). Moreover, immunohistochemical staining also strongly evidenced that PR-M in ovarian cancer tissues was more significantly expressed than that in adjacent ovarian tissues, and PR-M expressed in cytoplasm was more abundant in ovarian cancer (Fig. 1C).

The expression of PR-M in ovarian cancer tissue was more significant than that in normal ovarian tissue, and the maximum expression was achieved in SKOV3 cell line. Real-time PCR was used to determine the expression of PR-M mRNA in ovarian cancer and no-tumor tissues, as well as in ovarian cancer cell lines (3AO, ES-2, SKOV-3 and H08910) and normal cells (IOSE-80). As indicated by the results of real-time PCR, PR-M mRNA had overexpression in ovarian cancer tissues, and the expression of PR-M mRNA in SKOV3 cell line was the maximum. (Fig. 2) 


\section{PR-M promotes the proliferation of SKOV-3 ovarian cancer cell line}

SKOV3 cell lines (PR-A/B (-)) with the maximum PR-M expression were treated with different concentrations of progesterone. As revealed from the results, there was no significant difference in cell proliferation between the low concentration experimental group and the control group. As impacted by medium and high concentrations of progesterone, As revealed from the results, the proliferation activity of SKOV3 cells was stronger with the increase of progesterone concentration at the same time compared with the control group. Under the identical concentration of progesterone, with the prolongation of 24, 48 and $72 \mathrm{~h}$, the cell activity of SKOV3 cells was improved. For this reason, progesterone may promote the proliferation of ovarian cancer cells with high PR-M content. (Fig. 3)

\section{PR-M promotes the migration of SKOV-3 ovarian cancer cell line}

After $24 \mathrm{~h}$ and $48 \mathrm{~h}$ scratch tests were performed, compared with the control group, SKOV-3 cells in the group administrated with high-concentration progesterone migrated to the scratch site, demonstrating that PR-M facilitates cell migration as impacted by progesterone. (Fig. 4)

\section{Overexpression of PR-M is associated with clinical features of ovarian cancer}

Immunohistochemistry was performed for 12 cases of benign ovarian tumors, 8 cases of borderline tumors as well as 32 ovarian cancer cases. As revealed from the results, benign tissues and borderline tissues respectively achieved $33.3 \%$ and $50 \%$ weakly positive expression rates of PR-M (Table 1). However, the strong positive rate of PR-M in ovarian cancer reached $62.5 \%$ (Table 2), significantly higher than that in benign and borderline tumors (Fig. 5). As indicated by the results achieved by performing Fisher's exact test, patients exhibiting high PR-M expression were in stage III-IV ( $P=0.018)$, and lymph node metastasis $(P=0.006)$, intraperitoneal metastasis $(P=0.021)$ and elevated CA125 level $(P=0.037)$ might occur (Table 3). Furthermore, Spearman correlation analysis confirmed that high PR-M expression was related to $F I G O$ stage $(P=0.007)$, Lymph node metastasis $(P=0.012)$, Intraperitoneal metastasis $(P=0.022)$, as well as $C A 125(\mathrm{U} / \mathrm{mL})(P=0.031)$. As opposed to the mentioned, PR-M expression was not associated with age, histological type and other clinical features (Table 4). In brief, the mentioned suggest that PR-M may critically impact the development of ovarian cancer.

\section{Discussion}


Progesterone shows a correlation with the regulation of various reproductive processes (e.g., follicular growth, oocyte maturation, ovulation, implantation and maintenance of pregnancy). Moreover, it acts as a vital regulator of normal breast and breast cancer(22, 25, 26). The conventional idea is that steroids usually exert their gene transcription functions via their nuclear receptors(27). However, progesterone is also capable of having non-genomic effects on plasma membrane and cytoplasm outside the nucleus $(28,29)$. Progesterone was found with various rapid non-genomic regulatory functions (e.g., oocyte maturation induction, brain reproductive signal regulation, rapid activation of breast cancer cell signal, as well as acrosome reaction induction)(22, 30) . PR-M is a truncated PR supplemented by 314 amino acids. The transcription starts from intron 3 at the beginning of exon 4 of NPR. The amino terminal of the protein structure consists of a unique mitochondrial localization sequence of 16 aa. However, such PR subtype lacks DNA binding domain and nuclear localization sequence(16). As revealed from the results, the enrichment of PR-M showed a correlation with the distribution of mitochondria, and PR-M was significantly expressed in heart, liver and uterine smooth muscle $(23,31,32)$. Under the induction of progesterone, PR-M can hyperpolarize the mitochondrial membrane potential, which has been verified to be associated with the expression of PR-M in breast cancer cell lines mcf10a and T47D. ThomasM.Price The research team performed relevant experiments $(20,22)$.

Though PR-M is critical to regulate cell respiration, limited studies have been conducted on PR-M and ovarian cancer. Accordingly, the relationship between PR-M and ovarian cancer was preliminarily analyzed in this study. Real-time PCR and the Western blotting assay were performed for detecting the PR-M level in ovarian cancer and normal cell lines and tissues. In addition, the expression of PR-M protein was detected by performing immunohistochemistry. PR-M was up-regulated significantly in ovarian cancer cell lines and tissues compared with that of normal cells. The abnormal expression displayed a significant correlation with clinical stage, lymph node metastasis, intraperitoneal metastasis and CA125 level, demonstrating that high PR-M expression may affect the progression of ovarian tumors. In cell experiment, progesterone facilitated the proliferation and migration of SKOV-3 cells in a concentrationand time-dependent manner. As revealed from the mentioned, progesterone may increase mitochondrial membrane potential and intracellular ATP via PR-M, thus facilitating intracellular respiration.

Progesterone is likely to boost the growth of apoptotic cells by increasing cell respiration, as well as inhibit the apoptosis regulated by mitochondria. This situation may be that progesterone can inhibit the activation of FasL pathway by PR-M receptor, which leads to the decrease in caspase 3 / 7 level, thus preventing the cell from apoptosis $(33,34)$. Several studies indicated that progesterone can regulate the activity of mitogen activated protein kinase and promote cell proliferation through non-genomic action(35). Existing studies on PR-M in uterine leiomyoma showed that PR-M suppressed autophagy and apoptosis of uterine leiomyoma cells via Bcl-2 / Beclin1 axis(32, 36). In addition, the present study found that PR-M was expressed in ovarian cancer tissues and cells, whereas the mechanism of progesterone on PR-M receptor affected mitochondria and its specific pathway of inhibiting apoptosis were unclear. Further studies are required to verify the existence of the mechanism.

\section{Abbreviations}


PR-M Mitochondrial progesterone receptor

Real-Time PCR Real-time Polymerase Chain Reaction

CCK-8 Cell counting kit-8

PR Progesterone receptor

HGSC High-grade serous carcinoma

LGSC Low-grade serous cancer

OSE Ovarian surface epithelium

mPR Membrane progesterone receptor

PGRMC1 Progesterone receptor membrane component 1

cDNA Complementary DNA

SOC Serous ovarian cancer

SDS- PAGE Sodium dodecyl sulfate Polyacrylamide gel electrophoresis

TBST Tris-buffer saline with Tween

BSA Bovine serum albumin

BCA Bicinchoninic acid

FBS Fetal bovine serum

RPMI-1640 Roswell Park Memorial Institute-1640

nPR Nuclear progesterone receptor

L-P Low Progesterone

M-P Moderate Progesterone

H-P High Progesterone

EDTA Ethylene Diamine Tetraacetic Acid

DAB Diaminobenzidine

SD StandardDeviation 


$\begin{array}{ll}\text { ANOVA } & \text { Analysis of Variance } \\ \text { IDV } & \text { Integrated Density Value } \\ \text { FIGO } & \text { International Federation of Gynecology and Obstetrics } \\ \text { NPR } & \text { Nonexpresser of PR genes } \\ \text { aa } & \text { amino acids } \\ \text { ATP } & \text { Adenosine triphosphate }\end{array}$

Bcl-2 / Beclin1 B-cell leukemia/lymphoma 2

CA125 Carbohydrate antigen 125

CA199 Carbohydrate antigen 199

CA153 Carbohydrate antigen 153

CEA Carcino-embryonic antigen

\section{Declarations}

\section{- Ethics approval and consent to participate}

This study was approved by the Medical Ethics Committee of the Third Affiliated Hospital of Zhengzhou University (No. 2019045). All women provided written informed consent.

\section{- Consent to publish}

Not applicable.

\section{- Availability of data and materials}

All data generated or analyzed during this study are included in this published article [and its supplementary information files].

\section{- Competing interests}

The authors declare that they have no competing interests.

\section{- Funding}

The research is supported by the key scientific research project of Henan Province (No.20B320055). The funders had no role in the design of the study, in the collection, analysis, and interpretation of the data, or in the writing or approval of the manuscript. 


\section{- Authors' Contributions}

QY: Data Collection, Manuscript writing; CD: Data collection; HW: Data collection; DJ: Data analysis; YW: Data analysis; QT: Project development ; QF: Project development, Manuscript editing. All authors have read and approved the manuscript in its current state.

\section{- Acknowledgements}

None.

\section{- Authors' Information}

The email addresses of the authors

13663865573@163.com Qingqing Yang

845498009@qq.com Chang Duan

469165092@qq.com Haofan Wang

820456332@qq.com Dongyuan Jiang

wangyaping969@163.com Yaping Wang

zzutqf@126.com Qingfeng Tian

zzufql@126.com Quanling Feng

\section{References}

1. Ferlay J, Soerjomataram I, Dikshit R, Eser S, Mathers C, Rebelo M, et al. Cancer incidence and mortality worldwide: sources, methods and major patterns in GLOBOCAN 2012. Int J Cancer. 2015;136(5):E359-86.

2. Malvezzi M, Carioli G, Rodriguez T, Negri E, La Vecchia C. Global trends and predictions in ovarian cancer mortality. Ann Oncol. 2016;27(11):2017-25.

3. Claussen C, Rausch AV, Lezius S, Amirkhosravi A, Davila M, Francis JL, et al. Microvesicle-associated tissue factor procoagulant activity for the preoperative diagnosis of ovarian cancer. Thromb Res. 2016;141:39-48.

4. Mandai M, Hamanishi J, Abiko K, Matsumura N, Baba T, Konishi I. Anti-PD-L1/PD-1 immune therapies in ovarian cancer: basic mechanism and future clinical application. International Journal of Clinical Oncology. 2016;21(3):456-61.

5. Siegel RL, Miller KD, Jemal A. Cancer statistics. 2018. CA: A Cancer Journal for Clinicians. 2018;68(1):7-30. 
6. Matz M, Coleman MP, Sant M, Chirlaque MD, Visser O, Gore M, et al. The histology of ovarian cancer: worldwide distribution and implications for international survival comparisons (CONCORD-2). Gynecol Oncol. 2017;144(2):405-13.

7. Stewart C, Ralyea C, Lockwood S. Ovarian Cancer: An Integrated Review. Semin Oncol Nurs. 2019;35(2):151-6.

8. Czogalla B, Kahaly M, Mayr D, Schmoeckel E, Niesler B, Hester A, et al. Correlation of NRF2 and progesterone receptor and its effects on ovarian cancer biology. Cancer management research. 2019;11:7673-84.

9. Luo H, Li S, Zhao M, Sheng B, Zhu H, Zhu X. Prognostic value of progesterone receptor expression in ovarian cancer: a meta-analysis. Oncotarget. 2017;8(22):36845-56.

10. Lee K, Jeong J, Tsai MJ, Tsai S, Lydon JP, DeMayo FJ. Molecular mechanisms involved in progesterone receptor regulation of uterine function. J Steroid Biochem Mol Biol. 2006;102(1-5):4150 .

11. Jeon SY, Hwang KA, Choi KC. Effect of steroid hormones, estrogen and progesterone, on epithelial mesenchymal transition in ovarian cancer development. J Steroid Biochem Mol Biol. 2016;158:1-8.

12. Robinson-Rechavi M, Escriva Garcia H, Laudet V. The nuclear receptor superfamily. Journal of cell science. 2003;116(Pt 4):585-6.

13. Richer JK, Jacobsen BM, Manning NG, Abel MG, Wolf DM, Horwitz KB. Differential gene regulation by the two progesterone receptor isoforms in human breast cancer cells. J Biol Chem. 2002;277(7):5209-18.

14. Kim JJ, Kurita T, Bulun SE. Progesterone action in endometrial cancer, endometriosis, uterine fibroids, and breast cancer. Endocr Rev. 2013;34(1):130-62.

15. Wei LL, Gonzalez-Aller C, Wood WM, Miller LA, Horwitz KB. 5'-Heterogeneity in human progesterone receptor transcripts predicts a new amino-terminal truncated "C"-receptor and unique A-receptor messages. Molecular endocrinology (Baltimore Md). 1990;4(12):1833-40.

16. Saner KJ, Welter BH, Zhang F, Hansen E, Dupont B, Wei Y, et al. Cloning and expression of a novel, truncated, progesterone receptor. Molecular cellular endocrinology. 2003;200(1-2):155-63.

17. Hirata S, Shoda T, Kato J, Hoshi K. The novel exon, exon T, of the human progesterone receptor gene and the genomic organization of the gene. J Steroid Biochem Mol Biol. 2002;80(3):365-7.

18. Hirata S, Shoda T, Kato J, Hoshi K. The novel isoform of the progesterone receptor CDNA in the human testis and detection of its mRNA in the human uterine endometrium. Oncology. 2000;59(Suppl 1):39-44.

19. Neubauer H, Ma Q, Zhou J, Yu Q, Ruan X, Seeger H, et al. Possible role of PGRMC1 in breast cancer development. Climacteric: the journal of the International Menopause Society. 2013;16(5):509-13.

20. Dai Q, Shah AA, Garde RV, Yonish BA, Zhang L, Medvitz NA, et al. A truncated progesterone receptor (PR-M) localizes to the mitochondrion and controls cellular respiration. Molecular endocrinology (Baltimore Md). 2013;27(5):741-53. 
21. Wei LL, Miner R. Evidence for the existence of a third progesterone receptor protein in human breast cancer cell line T47D. Cancer research. 1994;54(2):340-3.

22. Price TM, Hansen EL, Oliver TN. Immunofluorescent localization of a novel progesterone receptor(s) in a T47D-Y breast cancer cell line lacking genomic progesterone receptor expression. J Soc Gynecol Investig. 2005;12(8):610-6.

23. Dai Q, Likes CE 3rd, Luz AL, Mao L, Yeh JS, Wei Z, et al. A Mitochondrial Progesterone Receptor Increases Cardiac Beta-Oxidation and Remodeling. Journal of the Endocrine Society. 2019;3(2):44667.

24. Charles NJ, Thomas P, Lange CA. Expression of membrane progesterone receptors (mPR/PAQR) in ovarian cancer cells: implications for progesterone-induced signaling events. Hormones cancer. 2010;1(4):167-76.

25. Taylor AH, McParland PC, Taylor DJ, Bell SC. The cytoplasmic $60 \mathrm{kDa}$ progesterone receptor isoform predominates in the human amniochorion and placenta at term. 7. Reproductive biology: RB\&E; 2009. p. 22.

26. Manuck TA, Price TM, Thom E, Meis PJ, Dombrowski MP, Sibai B, et al. Absence of mitochondrial progesterone receptor polymorphisms in women with spontaneous preterm birth. Reproductive sciences (Thousand Oaks. Calif). 2010;17(10):913-6.

27. Leonhardt SA, Boonyaratanakornkit V, Edwards DP. Progesterone receptor transcription and nontranscription signaling mechanisms. Steroids. 2003;68(10-13):761-70.

28. Peluso JJ, Fernandez G, Pappalardo A, White BA. Membrane-initiated events account for progesterone's ability to regulate intracellular free calcium levels and inhibit rat granulosa cell mitosis. Biol Reprod. 2002;67(2):379-85.

29. Peluso JJ. Progesterone receptor membrane component 1 and its role in ovarian follicle growth. Front NeuroSci. 2013;7:99.

30. Zhang L, Kanda Y, Roberts DJ, Ecker JL, Losel R, Wehling M, et al. Expression of progesterone receptor membrane component 1 and its partner serpine 1 mRNA binding protein in uterine and placental tissues of the mouse and human. Molecular cellular endocrinology. 2008;287(1-2):81-9.

31. Feng Q, Crochet JR, Dai Q, Leppert PC, Price TM. Expression of a mitochondrial progesterone receptor (PR-M) in leiomyomata and association with increased mitochondrial membrane potential. J Clin Endocrinol Metab. 2014;99(3):E390-9.

32. Liao S, Mi HN, Chai LY, Wang HN. Effects of progesterone receptor on proliferation of uterine leiomyoma cells. J Biol Regul Homeost Agents. 2019;33(6):1685-93.

33. Hanson BJ, Carrozzo R, Piemonte F, Tessa A, Robinson BH, Capaldi RA. Cytochrome c oxidasedeficient patients have distinct subunit assembly profiles. J Biol Chem. 2001;276(19):16296-301.

34. Giannoukos G, Szapary D, Smith CL, Meeker JE, Simons SS. Jr. New antiprogestins with partial agonist activity: potential selective progesterone receptor modulators (SPRMs) and probes for receptor- and coregulator-induced changes in progesterone receptor induction properties. Molecular endocrinology (Baltimore Md). 2001;15(2):255-70. 
35. Skildum A, Faivre E, Lange CA. Progesterone receptors induce cell cycle progression via activation of mitogen-activated protein kinases. Molecular endocrinology (Baltimore Md). 2005;19(2):327-39.

36. Zhang L, Feng Q, Wang Z, Liu P, Cui S. Progesterone receptor antagonist provides palliative effects for uterine leiomyoma through a Bcl-2/Beclin1-dependent mechanism. Bioscience reports. 2019;39(7).

\section{Tables}

\section{Table 1}

Expression of PR-M protein in ovarian tumors

\begin{tabular}{|llllll|}
\hline Tumor types & Number of Cases $₫ \mathrm{n})$ & $-(\%)$ & $+(\%)$ & $++(\%)$ & $+++(\%)$ \\
\hline Benign serous cystadenoma & 12 & $8(66.7)^{\star}$ & $4(33.3)$ & 0 & 0 \\
\hline Borderline serous cystadenoma & 8 & $4(50)$ & $4(50)$ & 0 & 0 \\
\hline Epithelial ovarian carcinoma & 32 & $5(15.6)$ & $7(21.9)$ & $15(46.9)$ & $5(15.6)$ \\
\hline
\end{tabular}

*Compared with the negative group of different types of tissue邓p $<0.05$

\section{Table2}

Clinicopathological characteristics and tumor expression of PR-M in epithelial ovarian cancer. 


\begin{tabular}{|ll|}
\hline Characteristic & Number of Cases (\%) \\
\hline Age (years) & \\
\hline$\leq 50$ & $12 \searrow 37.5 \rrbracket$ \\
\hline$>50$ & $20 \bigotimes 62.5 \rrbracket$ \\
\hline Histological type & \\
\hline Serous adenocarcinoma & $18(56.25 \rrbracket$ \\
\hline Mucoid adenocarcinoma & $6(18.75)$ \\
\hline Endometrial adenocarcinoma & $6(18.75)$ \\
\hline Clear cell carcinoma & $2(6.25)$ \\
\hline FIGO stage & \\
\hline I--II & $10(31.25)$ \\
\hline III-IV & $22(68.75)$ \\
\hline Lymph node metastasis & \\
\hline No & $11(34.4)$ \\
\hline Yes & $21(65.6)$ \\
\hline Intraperitoneal metastasis & \\
\hline No & $2(25)$ \\
\hline Yes & $2(37.5)$ \\
\hline tumor size (cm) & $20(62.5)$ \\
\hline$\leq 5 \mathrm{~cm}$ & \\
\hline$>5 \mathrm{~cm}$ & \\
\hline recurrence & \\
\hline No & \\
\hline Yes & \\
\hline Vital status (at last follow-up) & \\
\hline Dead & \\
\hline
\end{tabular}




\begin{tabular}{|ll|} 
High & $20(62.5)$ \\
\hline $\mathrm{CA} 125(\mathrm{U} / \mathrm{mL})$ & \\
\hline 35 & $5(15.6)$ \\
$\mathrm{CA} 199(\mathrm{U} / \mathrm{mL})$ & $27(84.4)$ \\
$\leq 35$ & \\
$>35$ & $18(56.25)$ \\
\hline $\mathrm{CA} 153(\mathrm{U} / \mathrm{mL})$ & $14(43.75)$ \\
\hline$\leq 25$ & \\
\hline$>25$ & $16(50)$ \\
\hline $\mathrm{CEA}(\mathrm{U} / \mathrm{mL})$ & $16(50)$ \\
\hline$\leq 5.0$ & \\
\hline$>5.0$ & $19(59.4)$ \\
\hline
\end{tabular}

FIGO, International Federation of Gynecology and Obstetrics

\section{Table3}

Correlation between PR-M expression and clinicopathological features of epithelial ovarian cancer. 


\begin{tabular}{|c|c|c|c|c|c|}
\hline \multirow[b]{2}{*}{ Characterisc } & & \multirow[b]{2}{*}{ Total } & \multicolumn{2}{|l|}{ PR-M } & \multirow[b]{2}{*}{$\begin{array}{l}\text { Fisher's Exact } \\
\text { Test } p \text { Value }\end{array}$} \\
\hline & & & $\begin{array}{l}\text { No or Weak } \\
\text { Expression(- } \\
\sim+)\end{array}$ & $\begin{array}{l}\text { Moderate or Strong } \\
\text { Expression } ₫++\sim+++\rrbracket\end{array}$ & \\
\hline \multirow[t]{2}{*}{ Age (years) } & $\leq 50$ & 12 & 7 & 5 & \multirow[t]{2}{*}{0.130} \\
\hline & $>50$ & 20 & 5 & 15 & \\
\hline \multirow[t]{2}{*}{ FIGO stage } & $|-I|$ & 10 & 7 & 3 & \multirow[t]{2}{*}{0.018} \\
\hline & III-IV & 22 & 5 & 17 & \\
\hline \multirow{3}{*}{$\begin{array}{l}\text { Lymph node } \\
\text { metastasis }\end{array}$} & No & 11 & 8 & 3 & \multirow[t]{3}{*}{0.006} \\
\hline & Yes & 21 & & 17 & \\
\hline & & & 4 & & \\
\hline \multirow{2}{*}{$\begin{array}{l}\text { Intraperitoneal } \\
\text { metastasis }\end{array}$} & No & 12 & 8 & 4 & \multirow[t]{2}{*}{0.021} \\
\hline & Yes & 20 & 4 & 16 & \\
\hline \multirow[t]{2}{*}{ tumor size $(\mathrm{cm})$} & $\leq 5 \mathrm{~cm}$ & 8 & 4 & 4 & \multirow[t]{2}{*}{0.433} \\
\hline & $>5 \mathrm{~cm}$ & 24 & 8 & 16 & \\
\hline \multirow[t]{2}{*}{ recurrence } & No & 25 & 10 & 15 & \multirow[t]{2}{*}{0.683} \\
\hline & Yes & 7 & 2 & 5 & \\
\hline \multirow{2}{*}{$\begin{array}{l}\text { Vital status (at } \\
\text { last follow-up) }\end{array}$} & Alive & 26 & 11 & 15 & \multirow[t]{2}{*}{0.37} \\
\hline & Dead & 6 & 1 & 5 & \\
\hline \multirow[t]{2}{*}{ CA125(U/mL) } & $\leq 35$ & 5 & 4 & 1 & \multirow[t]{2}{*}{0.037} \\
\hline & $>35$ & 27 & 7 & 20 & \\
\hline \multirow[t]{2}{*}{ CA199(U/mL) } & $\leq 35$ & 18 & 6 & 12 & \multirow[t]{2}{*}{0.718} \\
\hline & $>35$ & 14 & 6 & 8 & \\
\hline \multirow[t]{2}{*}{ CA153(U/mL) } & $\leq 35$ & 16 & 7 & 9 & \multirow[t]{2}{*}{0.716} \\
\hline & $>35$ & 16 & 5 & 11 & \\
\hline \multirow[t]{2}{*}{$\mathrm{CEA}(\mathrm{U} / \mathrm{mL})$} & $\leq 35$ & 19 & 8 & 11 & \multirow[t]{2}{*}{0.713} \\
\hline & $>35$ & 13 & 4 & 9 & \\
\hline
\end{tabular}


Correlation between PR-M expression and clinicopathological characteristics of epithelial ovarian cancer.

\begin{tabular}{|lll|}
\hline Variable & PR-M Expression & \\
\cline { 2 - 3 } & Spearman's Correlation Coefficient & p Value \\
\hline Age & 0.194 & 0.28 \\
\hline Histological type & -0.283 & 0.116 \\
\hline FIGO stage & 0.467 & 0.007 \\
\hline Lymph node metastasis & 0.437 & 0.012 \\
\hline Intraperitoneal metastasis & 0.402 & 0.022 \\
\hline tumor size $囚 \mathrm{~cm})$ & 0.150 & 0.413 \\
\hline recurrence & 0.144 & 0.432 \\
\hline Vital status (at last follow-up) & 0.185 & 0.311 \\
\hline CA125(U/mL) & 0.383 & 0.031 \\
\hline CA199(U/mL) & -0.065 & 0.722 \\
\hline CA153(U/mL & 0.137 & 0.722 \\
\hline CEA(U/mL) & 0.07 & 0.704 \\
\hline
\end{tabular}

Figures 
Figure 1

A

$$
\text { T47D } \frac{1}{T N} \frac{2}{T N} \frac{3}{N} \frac{4}{T N} \frac{5}{T N}
$$

PR-M

GAPDH

B

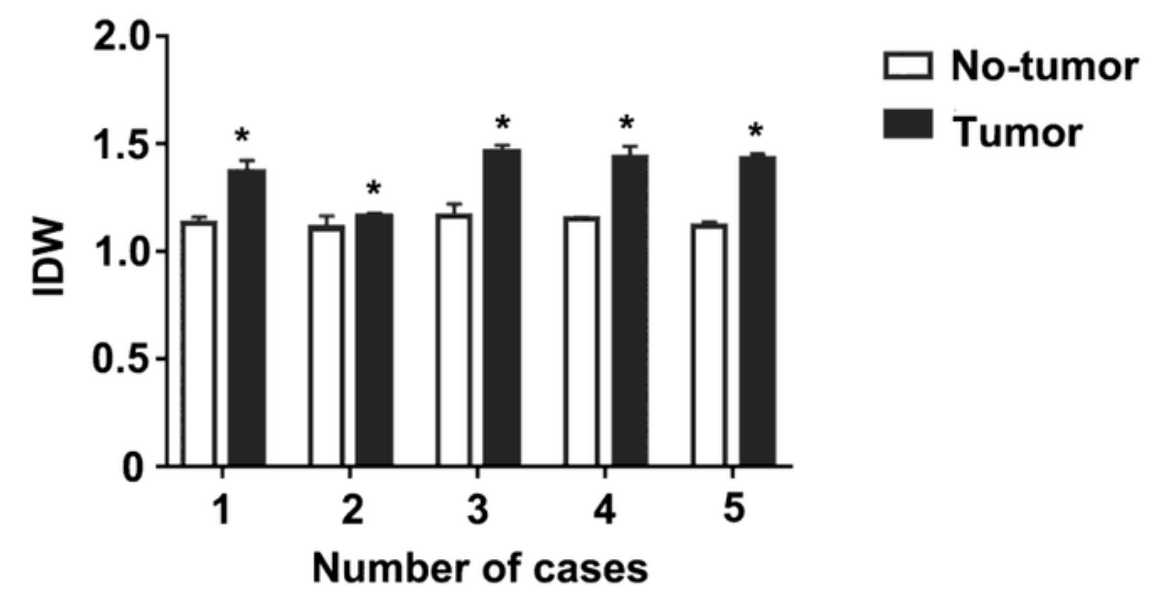

C

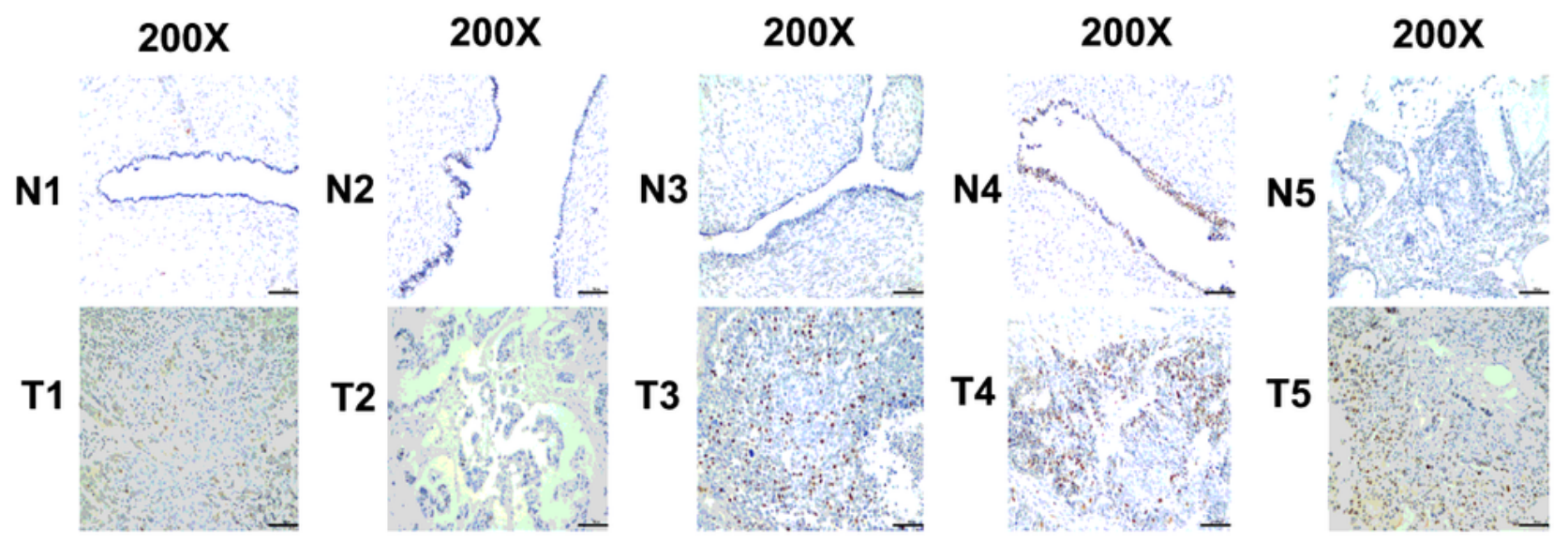

Figure 1

(A) 5 pairs of matched ovarian cancer $(T)$ and adjacent noncancerous tissue $(N)$ were used to represent the expression of PR-M protein. GAPDH was selected as the internal parameter.(B)Semi quantitative results showed that the IDV ratio of PR-M / GAPDH was greater than 1 in 5 patients.

(C)Immunohistochemical (IHC) assay of PR-M protein expression in 5 pairs of matched ovarian cancer tissues $(* p<0.05)$. 
Figure 2

A

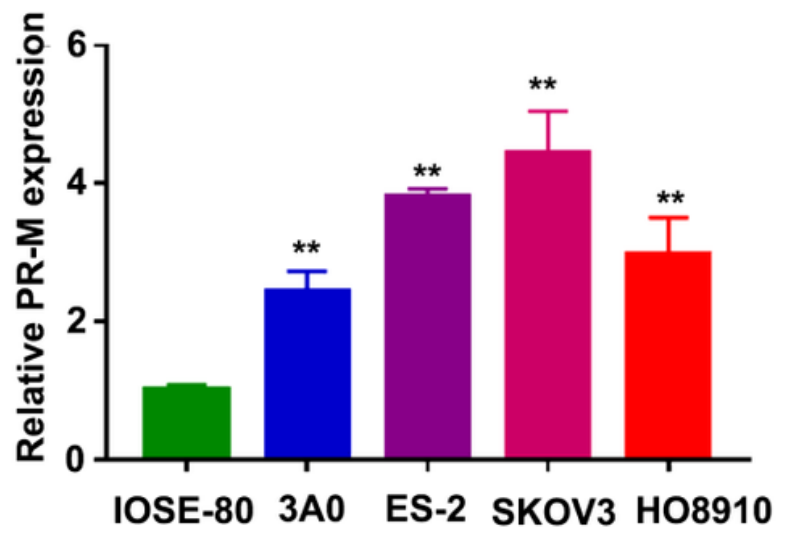

B

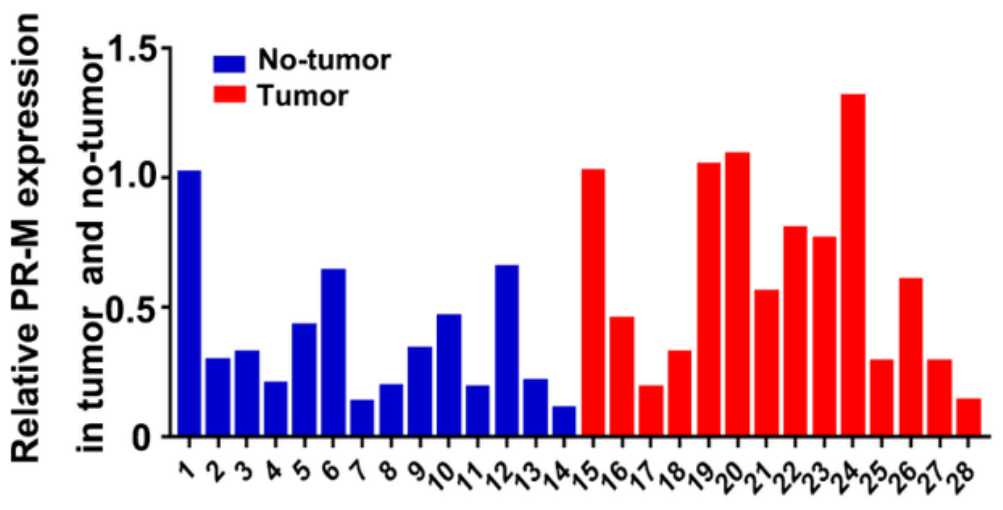

D

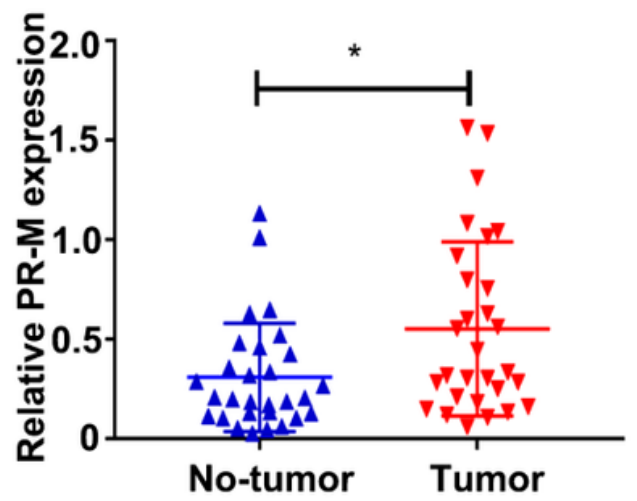

Figure 2

(A) The expression of PR-M mRNA in ovarian cancer cell line was significantly higher than that in normal

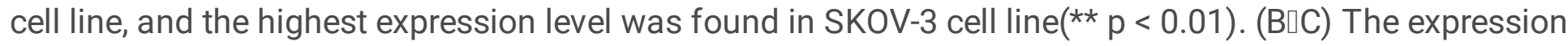
of PR-M mRNA in ovarian cancer tissues and no-tumor tissues. (D) The expression of PR-M mRNA in ovarian cancer tissues was significantly higher than that in no-tumor tissues $(* p<0.05)$. 
Figure 3

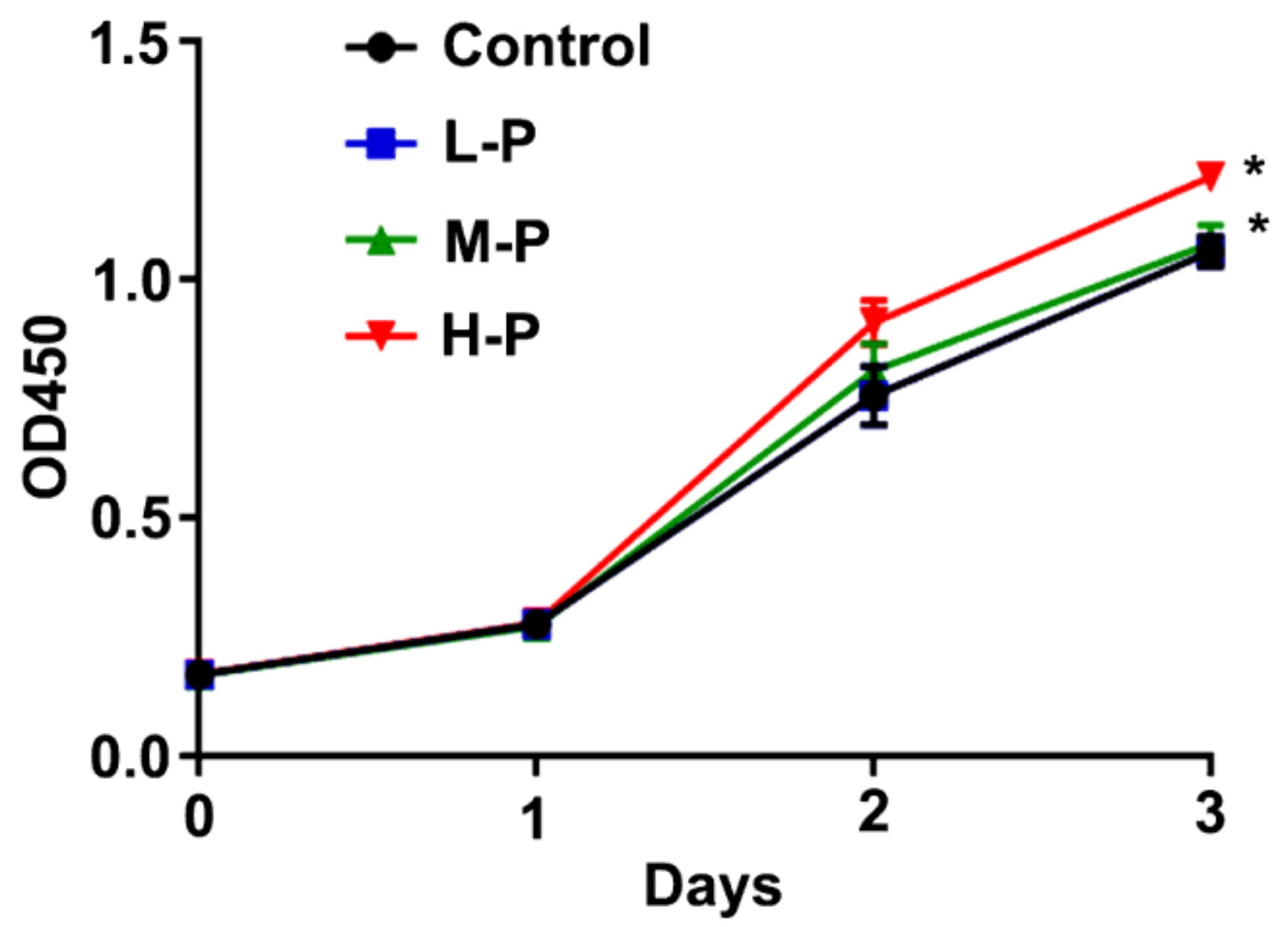

Figure 3

Compared with the control group, the cell proliferation activity showed a time effect and dose effect relationship. $\nabla^{*} p<0.05 \rrbracket$ 
Figure 4

A
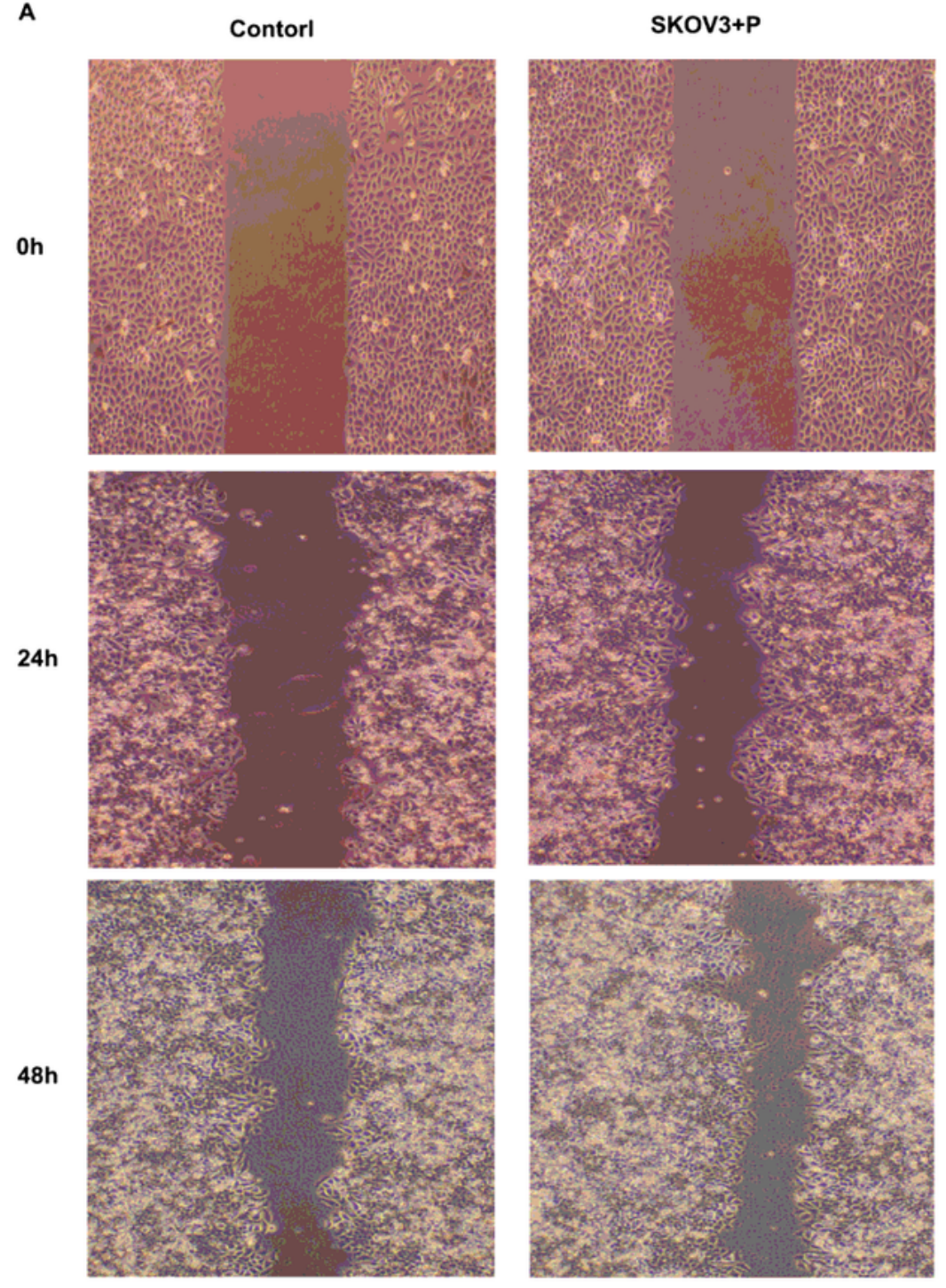

B

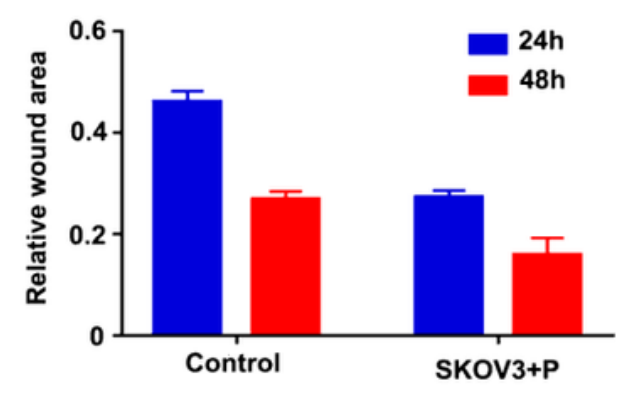

Figure 4

After $24 \mathrm{~h}$ and $48 \mathrm{~h}$ scratch test, SKOV-3 cells in progesterone treated group and control group migrated to the scratch, and the scratch spacing of progesterone treated group was the smallest, and there was significant difference between the group. $\rrbracket^{*} p<0.05 \rrbracket$ 
Figire 5

A1
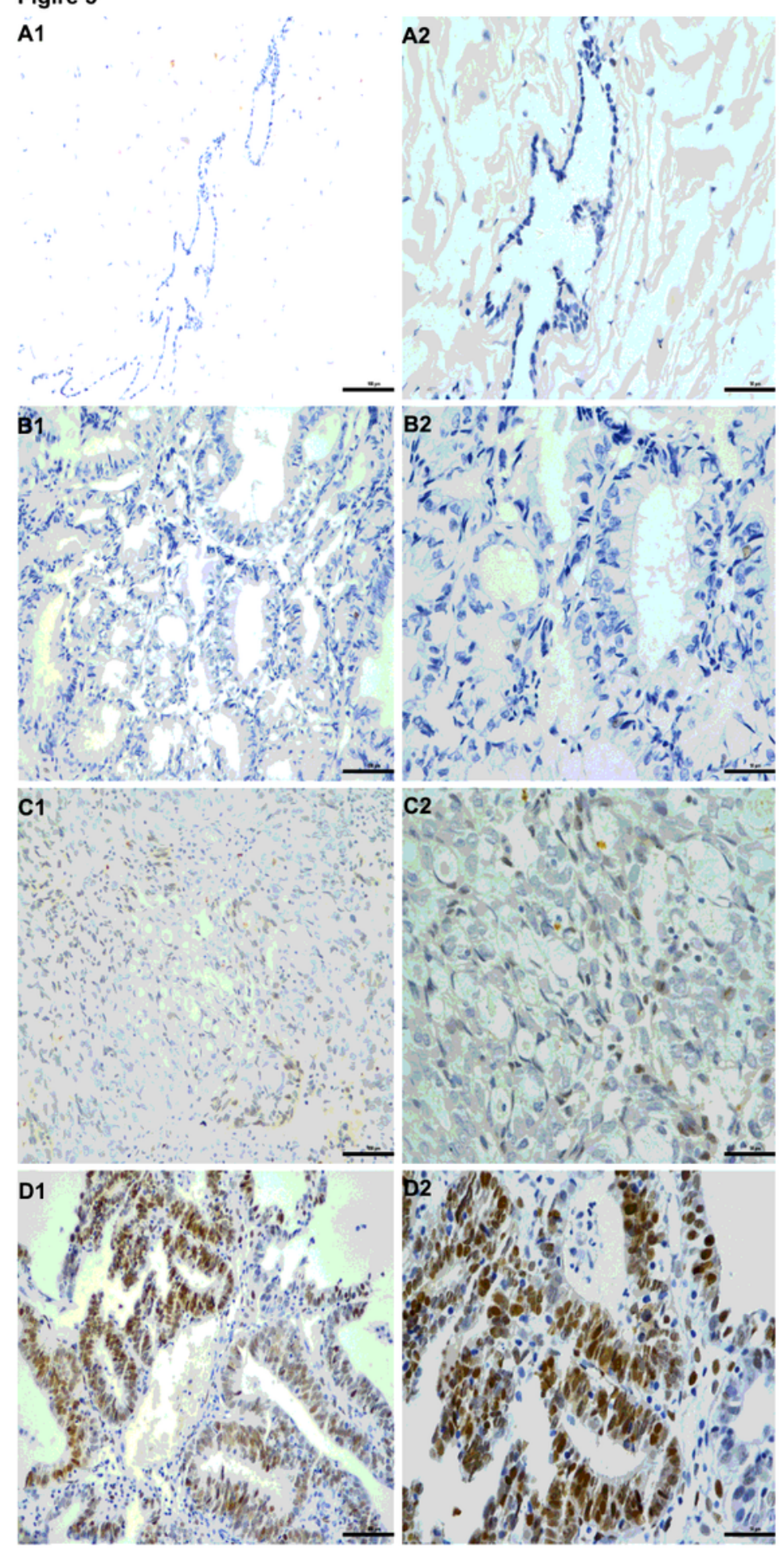

\section{Figure 5}

The expression of PR-M in paraffin embedded ovarian benign tumor, borderline tumor and ovarian cancer was detected by IHC. PR-M staining was mainly observed in cytoplasm. $(A, B)$ no PR-M expression or low expression was detected in ovarian benign tumors and borderline tumors; (C, D) typical images of weak PR-M staining in ovarian cancer tissues; (E, F) representative images of strong PR-M staining in ovarian cancer tissues. 


\section{Supplementary Files}

This is a list of supplementary files associated with this preprint. Click to download.

- renameded0a1.xlsx 